\title{
Att skapa åtgärder för att minska järnvägssjälvmord - är det möjligt?
}

Ved Helena Rådbo

\section{Järnvägen är en uppfinning som har bidragit till samhällets utveckling på många sätt. Tyvärr används denna resurs även till andra syften - att ta sitt liv. Järnvägsindustrin börjar se denna individuella tragedi som ett problem som även de har ansvar för att försöka förhindra.}

\begin{abstract}
Själmord inom järnvägstrafik är orsaken till ca $75 \%$ av alla personpåkörningar med dödlig utgång i Sverige. Detta drabbar samhället på flera sätt, offret som brottats med självmordstankar som till slut leder till handling, anhöriga och/eller andra personer i offrets närhet, likaså utgör självmord ett betydande problem för järnvägssektorn med stora förseningar som påverkar både resenärer, operatörer och spårförvaltare. Frågan är om dessa personpåkörningar kan förebyggas; är det möjligt att göra begränsningar i miljön för att göra det svårare att utnyttja järnvägen som en självmordsmetod? Prevention av järnvägssjälvmord har utvecklats i några svenska artiklar som presenteras här och dessa jämförs även med andra internationella vetenskapliga studier. Forskningen visar att det finns strategier för att skapa preventionsåtgärder som både försöker reducera attraktiviteten i metoden och som reducerar dödligheten. I aktuell sammanställning förs en diskussion kring ett antal möjliga åtgärder som systemägaren inom järnvägssektorn själva kan förfoga över. En konklusion är att det finns ett antal åtgärder som kan användas och utvecklas inom järnvägens ordinarie säkerhetsarbete.
\end{abstract}

Suicides constitute about $75 \%$ of all deaths in person-train collisions in Sweden. Besides the tragedy directly related to the victim, these events inflict severe trauma among relatives, professionals and others involved. The capacity of the rail transport system to operate timely and effectively is also hampered. Are these accidents preventable? Is it possible to take actions that make it more difficult to use the railway as a means to commit suicide? Railway suicide prevention has been developed in some Swedish articles and is also compared to other international research in this study. These articles summarize the results in the form of alternative preventative strategies, ranging from measures reducing the attractiveness of railway as a means of suicide to lethality reducing measures. Thus, the research demonstrates a number of potentially available strategies in the hands of the systems-owner. The most significant conclusion, therefore, is that suicide prevention should be seen as an integrated part of regular railway safety work.

LEVERT: 29.12.12 REVIDERT: 11/03-13 AKSEPTERT: 19/03-13

\section{Bakgrund}

Självmord framför tåg är något som ökat i takt med tågtrafikens utbyggnad. Inom EU uppskattas självmorden till $66 \%$ av alla dödade i samband med Järnvägstrafik (European Railway Agency, 2011). Järnvägssjälvmord drabbar samhället på flera sätt, offret som brottats med självmordstankar som till slut leder till handling, anhöriga och/eller andra personer i offrets närhet, likaså utgör självmord ett betydande problem för järnvägssektorn med stora förseningar som påverkar både resenärer, operatörer och spårförvaltare. Händelserna innebär också ett framstående arbetsmiljöproblem för lokförare och andra berörda yrkesgrupper i samband med olyckan (Briem et al., 2007; Cothereau et al., 2004; Limosin et al., 2006; Tang, 1994; Theorell et al., 1994).

I Sverige sker mer än ett självmord per vecka på det statliga järnvägsnätet mellan tåg i rörelse och person som befinner sig på järnvägsspåret (Lindberg 2012). Forskningen på området ökar mer och mer och diskussioner förs om möjligheterna att förebygga självmord med hjälp av förändringar i miljön kring spår och spårtrafik. En viktig forskning inom ämnet och som presenterar åtgärder har gjorts i doktorsavhandlingen Systeminriktad prevention av järnvägssjälvmord (Rådbo 2008).

Många av resultaten från den forskningen är utgångspunkt för aktuell artikel. Ingen av föreslagna åtgärder har dock utvärderats genom effektivitetsstudier. Många av de andra forskare som studerat järnvägssjälvmord har haft som utgångspunkt ett fokus på individen och dess ohälsa snarare än att försöka begränsa tillgången till en specifik metod. Att begränsa en metod är inget nytt och har praktiserats t ex genom att förändra sammansättningen i stadsgas, vapenlagar eller begränsad mängd föreskrivna receptbelagda mediciner. Inom spårtrafik försöker man göra förändringar i järnvägsmiljön och på så sätt göra järnvägen mindre attraktiv, men också försöka förhindra eller försvåra för en suicidal person att använda järnvägen för sina syften.

Om man kan påverka självmord och minska dödligheten genom att begränsa tillgången till en viss metod, debatteras ofta. Många hävdar att man åtminstone kortsiktigt kan påverka antalet självmord (Beskow 2000; Daigle, 2005; Reisch \&t Michel, 2005; Florentine \& Crane, 2010). Det är således inte självklart att en person som blivit berövad en metod automatiskt provar en annan (Daigle, 2005). Daigle (2005) hävdar i en omfattande forskningsöversikt att självmordstalen även kan påverkas på lång sikt. Han menar att personer som hindras i sitt suicidförsök inte självklart söker en annan metod, men det är av yttersta vikt att psykisk hjälp finns när ett självmordsförsök gjorts, eftersom forskning visar att de som tidigare gjort ett självmordsförsök ser ut att lättare göra ett nytt försök i nära anslutning till det första försöket (Daigle, 2005; 0' Donnell et al., 1994). I texten kommer fortsättningsvis både suicid och självmord användas, men avses handla om samma sak.

Syftet med denna sammanställning är att redovisa hur systeminriktad prevention av järnvägssjälvmord kan se ut genom att visa på kunskap, vetenskapligt forskning och strategier som ansvariga inom järnvägen själva kan använda sig av.

\section{Hur kan man påverka?}

Genom egna och andras studier av järnvägssjälvmord och prevention av dessa, samt diskussioner med berörda inom järnvägsbranschen, finns värdefull kunskap att lyfta fram.

I studier som gjorts i Sverige finns bland annat ett avhandlingsarbete som består av 4 vetenskapliga artiklar (Rådbo 2008 a). Den inledande studien är beskrivande epidemiologisk med fokus på när, var och hur järnvägssuicid har skett samt uppgifter om offret som skadats (Rådbo et al., 2005). 


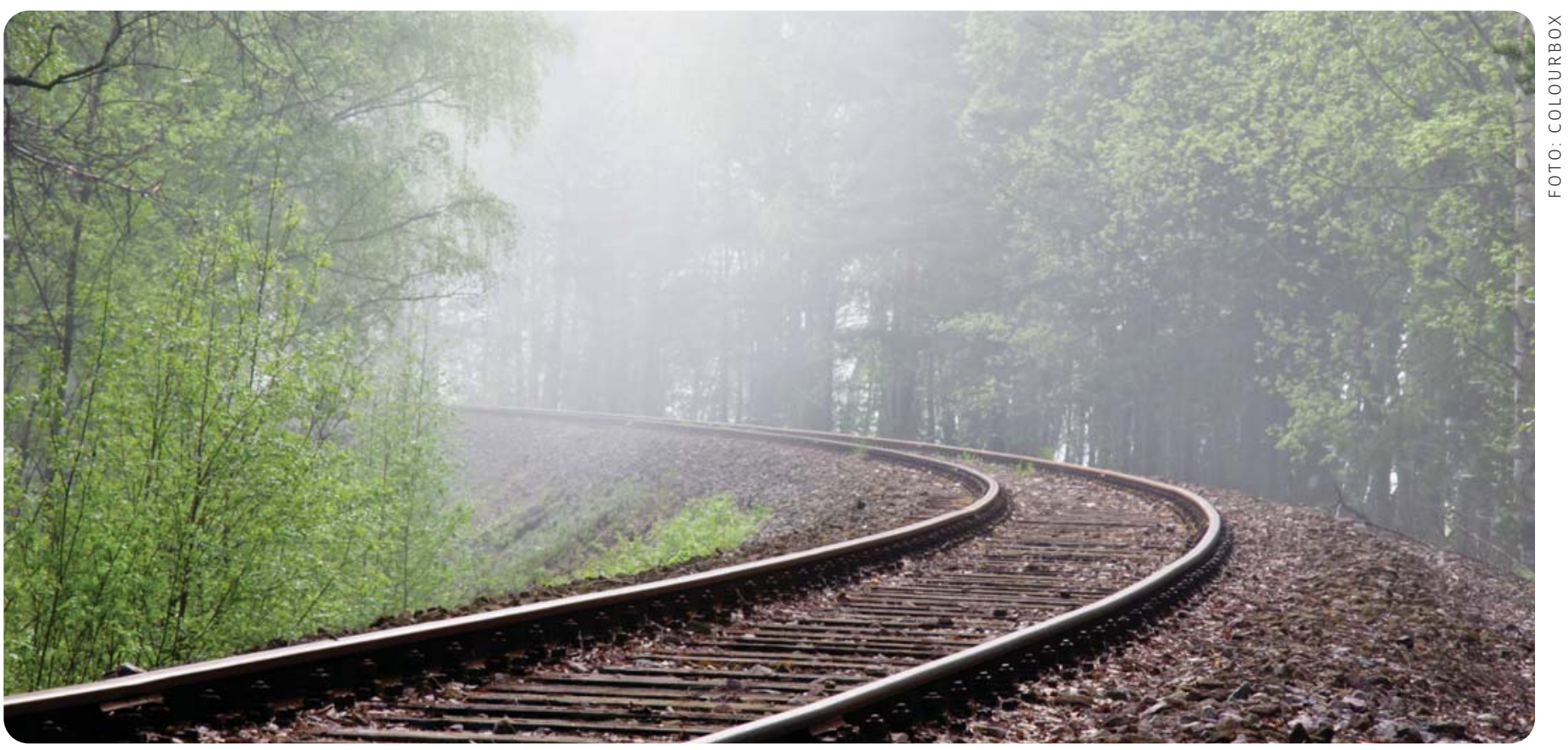

Kartläggningen är baserad på alla dödliga personpåkörningar under treårsperioden 2000-2002 som varit kända hos Trafikverket, dåvarande Banverket, totalt 192 fall fördelade på: 145 självmord (75,5 \%), 15 olycksfall (ca $8 \%$ ) och 32 fall med oklar avsikt $(16,5 \%)$, allt enligt polisens bedömning. Händelserna var relativt jämt fördelade över årets månader med någon förhöjning under sommarhalvåret, och vad gäller veckans dagar finns en svag trend inledningsvis på veckan. Tydligare framgår att självmord i större utsträckning inträffar dagtid, i samband med pendlartrafiken, medan olycksfallen oftare kan ske på kvällen och nattetid. Liknande mönster har påvisats bland andra forskare (Emmerson \& Cantor, 1993; Lerer \& Matzopoulos, 1997; Silla \&t Luoma, 2012). Utifrån detta material eller från andra studier kan man däremot inte se någon trend att fler suicid sker kring vissa tider på året, t ex storhelger. Däremot kan man se att järnvägssjälvmord är ett utpräglat tätortsproblem. Vidare framkom att suicidoffren ofta föreföll invänta tåget på spåret en tid innan tåget kommer. Detta tolkas som att en viss tidsrymd finns för att upptäcka person på fel plats. Jämförelsen mellan de tre skadekategorierna visar i övrigt små skillnader vilket talar för gemensamma åt- gärdsstrategier. Liknande åsikt framhåller även infrastrukturförvaltare när frågan har diskuterats i EU-projekt RESTRAIL (pågående 2011-2014). De menar att, orsaken till att en person befunnit sig på spåret är ointressant, det viktiga är att hindra alla från att skadas oavsett intention.

Delstudie 2 är en teoretisk analys med modellutveckling, för att få kunskap om vilka villkor som möjliggör respektive påverkar förloppet (Rådbo et al., 2008 b). Syftet var att teoretiskt utveckla och kategorisera ett antal preventionsåtgärder som systemägaren själv kan styra över. Metod för studien, se (ibid). Resultatet gav 21 olika teoretiska preventionsstrategier, indelat i fyra grupper. Åtgärder som avser reducera attraktionen av järnvägen som självmordsmetod, åtgärder som kan påverka tillgängligheten till spår och spårområden och möjligheter till kollision, åtgärder som kan mildra konsekvenserna av en kollision och åtgärder som berör strategier med avseende på vård och rehabilitering av skadade.

Tredje delarbetet utgör en kvalitativ flerfallsstudie av 22 järnvägssuicid som inträffat under två år inom ett avgränsat banområde (Rådbo et al., 2012 a). Metodmässigt innebar studien att samla så detaljerad information som möjligt kring varje fall för att få fördjupad förståelse/ kunskap om den speciella händelse som ett järnvägssjälvmord är. Syftet var att dels utvärdera befintliga dokument som Trafikverket (dåvarande Banverket) respektive polisen gjorde, för att se vilka uppgifter som kan användas för att förebygga olycka och dessutom se om ytterligare information fanns att hämta genom att undersöka platserna där påkörning skett. Studien resulterade i en rekommendation om vad som är viktiga och möjliga uppgifter att samla in när Polisen och Trafikverket utreder suicidhändelser på järnväg. Det som saknades och som enligt de egna djupstudierna visade sig möjligt och värdefullt att notera, är uppgifter om hur miljön ser ut och vilka andra omständigheter som kan ha underlättat för offret att ta sig till platsen.

Det fjärde arbetet utgörs av en fokusgruppsstudie (Rådbo et al., 2012 b). Syftet var att undersöka om de tidigare framtagna strategierna hade acceptans och relevans bland praktiskt verksamma säkerhetsexperter inom olika verksamhetsområden (järnväg, vägtrafik och räddningstjänst). Detta resulterade bl a i en diskussion om åtgärder som skulle kunna införas dels i dagsläget och dels på sikt. 
Åtgärder som kan införas med enklare medel i dagsläget är bland annat: information till allmänheten om vad som är tillåtet/ förbjudet, uppmana allmänheten att ringa 112 om man iakttar personer på "fel plats", se över rutiner när lokförare larmar om viktiga observationer längs spåret, kameraövervakning, underhåll av stängsel av olika slag, utökad stängsling inom tätorter. Åtgärder som kan vara möjliga på längre sikt kan vara ändrad design av tåg, omformning av plankorsningar i olika nivåer, sensorteknologi för detektering, omformning av plattformar, ljudoch ljussignaler som larmar när obehörig kommer in på förbjudet spårområde samt magnetbromsar på merparten av tågen. Studien innebar en validering av de tidigare framtagna strategierna i delstudie 2 (Rådbo et al., 2008 b) genom att deras principiella relevans bekräftades av praktiker.

Förutom de vetenskapliga studier som nämnts förekommer ett viktigt arbete inom vissa regioner i Sverige som bygger på samarbete mellan Trafikverket, Polisen, Räddningstjänst, psykvård och SOS alarm (Wibble et al., 2005). Vid hot om suicid eller om någon får kännedom om obehörig person inom spårmiljön som kan vara $\mathrm{i}$ fara, kan samtliga begära trafikstopp tills polis eller räddningstjänst har kunnat ta hand om personen. Denna åtgärd innebär ett trafikstopp på ca 10-15 minuter, vilket kan jämföras med om en person blir påkörd då trafiken kan stå stilla och/eller påverkas 1,5-2 timmar. Till skillnad mot t ex staket eller varningstavlor av olika slag bygger detta arbetet på att någon annan än enbart den suicidala personen reagerar och på så sätt styr utgången. Genom detta arbetssätt är det "systemet/omgivningen" som ska vara mer förlåtande, upptäcka och agera om någon är på fel plats.

\section{Sammanfattande diskussion}

Att förebygga självmord i samband med järnvägstrafik kan vara möjligt. Det finns inte en åtgärd som kan göra skillnad, utan många i kombination. Framför allt är det viktigt med ett samarbete mellan olika organisationer inom samhället, såsom banförvaltare, polis, räddningstjänst och SOS-alarm. Fokus i aktuell forskning är järnvägstransportsystemet. Samtidigt framtonar en problematik kring gränsytan och samspelet mellan detta system och det omgivande samhället, vilket visar på vikten av gemensamma strategier. I den fortsatta diskussionen tas utgångspunkt i denna indelning (Figur 1).

Figur 1. Sammanfattande bild av systeminriktade åtgärder för självmordsprevention inom järnvägstrafik.

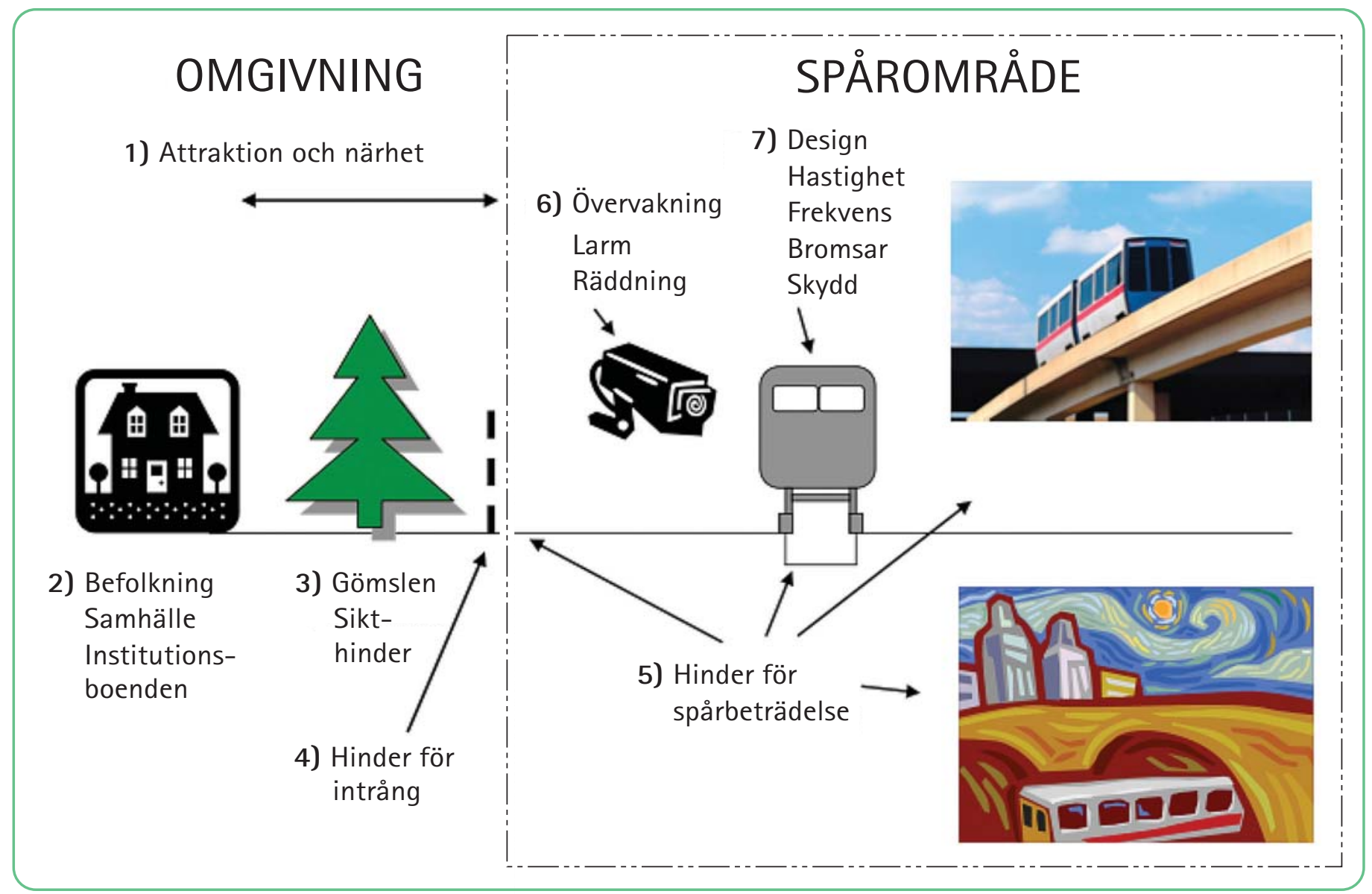




\section{Omgivning}

Till omgivningen hör befolkningen och därmed indirekt frågan om vad som framkallar järnvägens attraktion som självmordsmetod hos vissa suicidala personer (nr 1, Figur 1). Här kan delvis spekuleras och delvis stödjas på egen och andras forskning. En faktor tycks ligga i det allvarliga våld och den höga dödlighet som metoden antas innebära. I en brittisk studie har personer som överlevt självmordsförsök inom tunnelbanan intervjuats varvid framkom att det är det definitiva i metoden som lockar (0' Donnell et al., 1994; O' Donnell et al., 1996).

Till exponeringsbilden hör även förekomsten av institutionsboenden för utsatta grupper med särskild sårbarhet i detta avseende. Kopplingen mellan olika vårdboenden nära järnväg och suicidfrekvens på järnväg är belagd i andra studier (Frisk, 1997; Symonds, 1994; Kerkhof, 2003). På flera platser bedriver kommuner och privata boenden sin verksamhet. Som preventionsåtgärd kan det vara viktigt att överväga var olika boenden utlokaliseras och hur nära det är till järnvägen (nr 2, Figur 1).

I miljön kring järnvägsområdet aktualiseras frågor som berör flera parter, såsom ansvaret för stängsling, undanröjning av vegetation som kan skapa sikthinder för lokförare samt insynsskydd för den som vill hålla sig gömd (nr 3, Figur 1). Valet av järnväg som metod kan vara attraktivt för att den ofta är lättillgänglig (avsaknad av hinder eller lättforcerade sådana), och att det vanligtvis finns goda möjligheter att undandra sig uppmärksamhet under den slutliga förberedelsen medan tåg inväntas (nr 3, Figur 1) (Rådbo et al., 2012 a). Vidare aktualiseras ansvaret för information till allmänheten om vad som är tillåtet och inte tillåtet, vad gäller spårbeträdelse. Endast på avsedda platser får spåret korsas, i övrigt får bara behörig personal med varselklädsel vistas på spårområdet. Öppenhet kring spåret kan också utgöra en verkningsfull mental barriär för suicidala personer som söker avskildhet för sin slutliga förberedelse och väntan på tåg. Öppenheten är också en förutsättning för effektiv övervakning, social kontroll och räddningsinsats.

För att begränsa obehörig spårbeträdelse finns ibland hinder för intrång inom tätort (nr 4, Figur 1). Detta är en så kallad passiv åtgärd som ska hindra personer att ta sig in på spårområdet. Inom större städer kan det röra sig om staket eller bullerplank som ibland är kraftiga, men som även kan vara av mera symboliskt slag eller till och med saknas helt. Lärdomen från studierna är att ordentliga staket är en viktig barriär, inte minst genom att dessa utgör en tydlig markering om var skiljelinjen går mellan omgivning och spårområde.

Närheten till spåret är uppenbarligen en annan faktor som påverkar valet av järnvägen som självmordsmetod. I den deskriptiva studien (Rådbo et al., 2005) framkom att påkörningarna sker i stor utsträckning inom tätort, och att flest fall inträffar i storstäderna Stockholm, Göteborg och Malmö. Detta visar på att åtgärder, såsom stängsling, kan prioriteras mot geografiskt relativt avgränsade områden.

\section{Spårområde}

I Figur 1 har spårområdet definierats som det område som Trafikverket förvaltar.

Inom detta område är det av säkerhetsskäl förbjudet att vistas för utomstående förutom på avsedda platser såsom plattformar och plankorsningar. För att få vetskap om obehörig spårbeträdelse kan kameraövervakning användas, men också upptäckt från allmänheten och lokförare som ser personer i närheten av spåret och larmar (nr 6, Figur 1). Avlägsnandet kan ske på olika sätt; antingen genom eget beslut efter att man uppmärksammats på sin olovliga belägenhet eller ångrar sig och flyr situationen, eller också genom att någon handgripligen avlägsnar personen som gjort intrång. Inom vissa områden i Sverige har samarbete mellan räddningstjänst, polis och psykiatri upparbetas och vid larm om hot om suicid görs trafikstopp via SOS, så polis kan avlägsna obehörig person i spårområdet (Wibble et al., 2005).

Förutom staket (nr 4, Figur 1) kan också andra fysiska barriärer tänkas. En åtgärd är fysiska barriärer som separerar personer från tågtrafiken genom att bygga och lägga trafiken på upphöjda spår över marken eller under jord i tunnlar (nr 5 , Figur 1).

Även tågets design och framfart har betydelse (nr 7, Figur 1). I fokusgruppsintervjuerna omvittnades att människor skadas på olika sätt vid påkörning beroende på tågmodell (Rådbo et al., 2012b). Vid lägre hastigheter har konstaterats att flera personer har överlevt, troligen delvis beroende på tågfrontens design (ibid).

Hastighet och bromskapacitet är egenskaper som hänger samman. Ju högre hastighet desto längre blir bromssträckan om inte bromskapaciteten samtidigt förbättras. För att en kollision ska undvikas måste tåget gå väldigt sakta från början eller att lokföraren i tid fått en indikation på att någon är på spåret och hinner sakta ner eller stanna helt. Om varningssystem skulle kunna kombineras med andra åtgärder kan lokförarens möjligheter öka för att stanna i tid eller bromsa tillräckligt för att människoliv ska kunna räddas.

\section{Konklusion}

Självmord på järnväg framstår som möjliga att förebygga inom järnvägssystemets ram, såväl i teorin som i praktiken.

Teoretiskt har ett antal tänkbara barriärer utvecklats, vilka var för sig eller i kombination bör kunna bidra till en minskning av händelsernas antal och/eller allvarlighet. Flera av dessa har också potential att förebygga olycksfall, vilket är en fördel bland annat med tanke på att det finns en gråzon mellan dessa båda skadetyper. Detta anknyter till den teoretiskt intressanta diskussionen om att suicid också kan ses som olycksfall (Beskow 2008). 
Praktiskt visar resultaten i studierna bland annat att:

a) åtgärder kan prioriteras mot geografiskt relativt avgränsade områden,

b) det tycks finnas ett tidsmässigt utrymme för tidig detektion,

c) det finns ett utrymme för förbättrade händelseutredningar ur åtgärdssynpunkt,

d) de teoretiskt utvecklade strategierna möts av acceptans och förståelse bland säkerhetssakkunniga inom såväl järnvägen som andra verksamhetsområden, även om vissa bedöms som mer realistiska och framkomliga än andra.

Det bör därmed sammanfattningsvis finnas goda möjligheter att introducera ett mer systematiskt självmordförebyggande arbete inom järnvägssystemets ram som en del i det reguljära säkerhetsarbetet. Att praktiskt omsätta, implementera och utvärdera dessa strategier kvarstår i vissa delar medan andra utvecklats inom olika projekt, vilket innebär att ett viktigt fortsatt utvecklingsarbete pågår, men också kontinuerligt måste fortsätta.



Helena Rådbo, PhD

Folkhälsovetenskap forskar kring suicidproblematik inom spårtrafik i Sverige. Helena arbetar som lektor inom ämnet Riskhantering vid Karlstads universitet. Tillsammans med Trafikverket och ytterligare 17 parter deltar hon också i ett EU-projekt, Restrail, som avser visa på åtgärder för att reducera dödsfall inom järnvägen.

\section{Referanser}

Beskow, J., 2000. Nationellt program. In J. Beskow (Ed.), Självmord och självmordsprevention $0 m$ livsavgörande ögonblick (Suicide and suicide prevention). Lund: Studentlitteratur.

Beskow, J., 2008. Suicid som psykiskt olycksfall: ett systemperspektiv. Suicidologi; 13(3): 14-18.

Beskow, J., Thorson, J., \&t Östrom, M., 1994. National suicide prevention programme and railway suicide. Soc Sci Med 38(3):447-51.
Briem, V., de Lima, S., \&t Siotis, C. (2007). Train drivers and fatal accidents on the rails: Psychological aspects and safety. In J. R. Wilson, B. Norris, T. Clarke \&t A. Mills (Eds.), People and rail systems, human factors at the heart of the railway. Hampshire, England: Ashgate Publishing Limited.

Coats, T., \& Walter, D., 1999. Effect of station design on death in the London Underground: observational study. BMJ, 319:957.

Cothereau, C., de Beaurepaire, C., Payan, C., Cambou, J. P., Rouillon, F., \& Conso, F. (2004). Professional and medical outcomes for french train drivers after "person under train" accident: Three year follow up study. Occup Environ med. 61, 488-494.

Daigle, M. S. (2005). Suicide prevention through means restriction: Assessing the risk of

substitution A critical review and synthesis. Accid Anal Prev, 37, 625-632.

Emmerson, B., \& Cantor, C. (1993). Train suicides in Brisbane, Australia, 1980-1986. Crisis, 14(2), 90-94.

European Railway Agency. (2011). Railway safety performance in the European union. The Publications Office of the European Union, Luxembourg.

Florentine, J. B., \&t Crane, C. (2010). Suicide prevention by limiting access to methods: A review of theory and practice. Soc Sci Med, 70, 1626-1632.

Frisk, M., 1997. Olycka, självmord eller rop på hjälp? 173 dödsfall i järnvägstrafiken under 1990-95. Läkartidningen Mar 12;94(11) 973-4, 979-80.

Haddon, W., 1973. Energy damage and the 10 countermeasure strategies. J Trauma, 13, 321331.

Haddon, W. J., 1980. The Basic Strategies for Reducing Damage from Hazards of All Kinds. Hazard prevention 16, September-October.

Kerkhof, A. (2003). Railway suicide: Who is responsible? Editorial. Crisis, 24(2), 47-48.

Lerer, L. B., \& Matzopoulos, R. (1997). Fatal railway injuries in Cape Town, South Africa. Am J Forensic Med Pathol, 18(2), 144-147.

Lindberg (2012). Prevention av suicid i transportsystemet. Del av planeringsunderlag trafiksäkerhet. Version 2.1 (EL 2012-02-03) Trafikverket Hämtad frånhttp://www.trafikverket.se/PageFiles/ 68053/planeringsunderlag_prevention_av_suicid _i_transportsystemet.pdf

Limosin, F., Loze, J. Y., Cothereau, C., De Beaurepaire, C., Payan, C., Conso, F., et al. (2006). A prospective study of the psychological effects of "person under train" incidents on drivers. J Psychiatr Res, 40(8), 755-761.

O' Donnell, I., Arthur, A., \&t Farmer, R. (1994). A follow-up study of attempted railway suicides. Soc Sci Med, 38(3), 437-442.

O' Donnell, I., Farmer, R., \&t Catalan, J. 1996. Explaining suicide: the views of survivors of serious suicide attempts. Br J Psychiatry 168(6): 780-786.
Reisch, T., \& Michel, K. (2005). Securing a suicide hot spot: Effects of a safety net at the Bern Muenster terrace. Suicide Life-Threat Behav, 34(4), 460-467.

Rådbo, H. (2008 a). Systeminriktad prevention av järnvägssjälvmord Strategiutveckling i en Svensk kontext. Karlstad University Studies 2008:34, Karlstad.

Rådbo, H., Renck, B., \& Andersson, R. (2012 b). Feasibility of railway suicide prevention strategies; a focus group study. In C. Bérenguer, A. Grall \& C. Soares (Eds.), Advances in safety, reliability and risk management. London: Taylor \&t Francis Group.

Rådbo, H., Svedung, I., \&t Andersson, R., 2005.

Suicides and other fatalities form train-person collision on Swedish railroads: A descriptive epidemiologic analysis as a basis for systemsoriented prevention. Journal of Safety Research, $36,423-428$.

Rådbo, H., Svedung, I., \&t Andersson, R. (2008 b). Suicide prevention in railway systems: Application of a barrier approach. Safety Science, 46, 729-737.

Rådbo, H., Svedung, I., Ct Andersson, R. (2012 a). Suicide and potentials for suicide prevention on the swedish rail network; a qualitative multiple case study. In C. Bérenguer, A. Grall \& C. Soares (Eds.), Advances in safety, reliability and risk management. London: Taylor \&t Francis group.

Silla, A., \& Luoma, J. (2012). Main characteristics of train-pedestrian fatalities on Finnish railroads. Accid Anal Prev, 45, 61-66.

Symonds, R., 1994. Psychiatric and preventative aspects of rail fatalities. Soc Sci Med, 38(3): 431-5.

Tang, D. (1994). Psychotherapy for train drivers after railway suicide. Soc Sci Med, 38(3), 477478.

Theorell, T., Leymann, H., Jodko, M., Konarski, K., \&t Norbeck, H. (1994). Person under train incidents from the subway driver's point of view -a prosective 1-year follow-up study: The design, and medical and psychiatric data. Soc Sci Med 38(3), 471-475.

Wibble, T., Melin, G., Petersson, A., \& Lagerqvist, J., 2005. Samverkan mellan polis, sjukvård, SOS Alarm och räddningstjänst vid hot om suicid. Ett exempel från Jönköpings län. Karlstad: Räddningsverket.

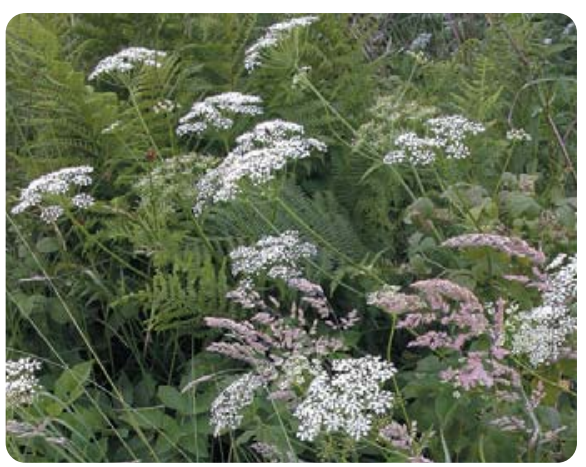

